\title{
Understanding the relationship between access to care and facility-based delivery through analysis of the 2008 Ghana Demographic Health Survey
}

\author{
Cheryl A. Moyer ${ }^{\mathrm{a}, \mathrm{b}, *}$, Zoë M. McLaren ${ }^{\mathrm{b}}$, Richard M. Adanu ${ }^{\mathrm{c}}$, Paula M. Lantz ${ }^{\mathrm{d}}$ \\ a Global REACH and Department of Medical Education, University of Michigan Medical School, Ann Arbor, USA \\ ${ }^{b}$ Department of Health Management and Policy, University of Michigan School of Public Health, Ann Arbor, USA \\ c School of Public Health, University of Ghana, Legon, Ghana \\ ${ }^{\mathrm{d}}$ Department of Health Policy, George Washington University School of Public Health, WA, USA
}

\section{A R T I C L E I N F O}

\section{Article history:}

Received 20 February 2013

Received in revised form 26 March 2013

Accepted 22 May 2013

\section{Keywords:}

Access to care

Africa

Facility-based delivery

Ghana

Low-income countries

Maternal and child health

Healthcare utilization

\begin{abstract}
A B S T R A C T
Objective: To determine the types of access to care most strongly associated with facility-based delivery among women in Ghana. Methods: Data relating to the "5 As of Access" framework were extracted from the 2008 Ghana Demographic Health Survey and analyzed using multivariate logistic regression. Results: In all, $55.5 \%$ of a weighted sample of 1102 women delivered in a healthcare facility, whereas $45.5 \%$ delivered at home. Affordability was the strongest access factor associated with delivery location, with health insurance coverage tripling the odds of facility delivery. Availability, accessibility (except urban residence), acceptability, and social access variables were not significant factors in the final models. Social access variables, including needing permission to seek healthcare and not being involved in decisions regarding healthcare, were associated with a reduced likelihood of facility-based delivery when examined individually. Multivariate analysis suggested that these variables reflected maternal literacy, health insurance coverage, and household wealth, all of which attenuated the effects of social access. Conclusion: Affordability was an important determinant of facility delivery in Ghana-even among women with health insurance-but social access variables had a mediating role.
\end{abstract}

(C) 2013 International Federation of Gynecology and Obstetrics. Published by Elsevier Ireland Ltd. All rights reserved.

\section{Introduction}

The majority of maternal and neonatal deaths occur during or shortly after delivery. Encouraging pregnant women in low-income countries to deliver at healthcare facilities is, therefore, considered an effective way to combat this issue [1].

Many factors relate to facility-based delivery, including the number of previous births [2,3], maternal age [2], household wealth [4,5], rural versus urban residence [6-8], and level of education $[4,9,10]$. "Access to care" is also an important determinant; however, it is typically described in terms of distance to the nearest facility, the ability to find transport, and whether women are insured or can afford the services provided. A meaningful discussion of what access to care encompasses for women living in Sub-Saharan Africa is still lacking.

The " 5 As of Access" is a conceptual framework that considers 5 factors influencing access to healthcare [11]. Affordability covers the ability and willingness of patients to pay for the services provided. Availability

\footnotetext{
* Corresponding author at: Global REACH and Department of Medical Education, University of Michigan Medical School, 5115 Med Sci 1, 1301 Catherine Street, Ann Arbor, MI 48109-5611, USA. Tel.: +1 734615 2838; fax: +1 7346156300 .

E-mail address: camoyer@umich.edu (C.A. Moyer).
}

considers the extent to which healthcare providers possess the technology and personnel resources to meet the needs of patients. Accessibility refers to ease of travel to the healthcare provider (e.g. distance to the facility and availability of transport). Accommodation considers the extent to which healthcare providers can meet the constraints and preferences of individual patients (e.g. hours of operation, how communications are handled, and whether appointments are required). Finally, acceptability is the degree to which patients are comfortable or uncomfortable with the characteristics of the healthcare provider (e.g. age, sex, social class, and ethnicity) [11,12] (Table 1 ).

It was hypothesized that the 5 As of Access framework could be applied to data obtained by the 2008 Ghana Demographic Health Survey (DHS) in order to examine the relationship between access factors and facility-based delivery among women who had given birth within the previous year. In addition, this proposed research would explore the relative merit of an additional category of "social access," defined as the extent to which social and cultural factors influence healthcareseeking behaviors. The 2008 Ghana DHS included several questions related to affordability, availability, accessibility, and acceptability, but none related to accommodation. These 4 access factors could potentially be explored in a multivariate model. In addition, the 2008 Ghana DHS included a number of questions regarding social access.

The aims of the present study were to identify access factors strongly associated with facility-based delivery among women in Ghana and to 
determine whether social access factors have sufficient explanatory power to be included in a model of facility-based delivery.

\section{Materials and methods}

The 2008 Ghana DHS was a nationally representative demographic health survey that recruited 4916 women aged $15-49$ years. The sample population analyzed in the present study was weighted [13] to account for the complex design of the 2008 Ghana DHS. The present study relied upon secondary analysis of anonymous, publicly available data. As a consequence, it was exempt from the processes of ethical review and informed consent.

Participants completed detailed interviews about a variety of health-related topics. The dependent variable of interest was "place of delivery," which was associated with 10 different response options in the 2008 Ghana DHS. All response options reflective of deliveries in any healthcare setting (e.g. private hospital, district hospital, regional health center, health post) were collapsed into a single category to reflect deliveries in any facility. All response options reflective of deliveries outside a healthcare setting (e.g. respondent's home, other home) were collapsed to reflect non-institutional delivery.

Sociodemographic factors included age-related variables, number of previous births, education level, marital status, household wealth, religion, and ethnicity. Table 1 illustrates the categories of access evaluated, as well as the 2008 Ghana DHS items used for measurement. Social access was assessed through 3 primary items: needing permission to seek healthcare, not wanting to go to a healthcare facility alone, and level of participation in the final decision regarding healthcare.

Data were analyzed using STATA version 11.1 (StataCorp, College Station, TX, USA). Univariate and bivariate statistics were calculated for demographic variables, health and health system utilization variables, and potential access barriers. The final weighted sample for the multivariate regression analyses excluded all women with missing data on any of the key variables found to be significant in the bivariate analysis. Multivariate logistic regression was conducted with clusters of similar variables to identify the related variables most strongly associated with facility-based delivery. The access-related clusters examined were limited to those factors found to be significant in the bivariate analysis. Variables found to be significant $(P<0.05)$ within their clusters were carried forward for inclusion in the comprehensive models. Forward stepwise multivariate logistic regression was conducted using the strongest predictors from each cluster to create a final model of facility-based delivery.

\section{Results}

Of the 4916 women recruited to the 2008 Ghana DHS, 2992 reported on the location of their previous delivery, 1177 reported giving birth within the past year, and 1161 indicated that their delivery was either at home or in a facility setting. The final weighted sample comprised 1102 women.

Table 2 shows the sociodemographic characteristics stratified by place of delivery. Across the sample as a whole, women had a mean age of 29 years, more than 3 previous births, and first experienced delivery at approximately 20 years of age. In all, $55.5 \%$ of the women had delivered their most recent child in a healthcare facility. Women who delivered in healthcare facilities were more likely to be better educated, more literate, live in an urban area, identify as a Christian, be in a non-polygamous union, and have partners with higher education level than the women who delivered at home. Women delivering in healthcare facilities also had fewer previous births, were older at the time of their first birth, and had more prenatal care visits than women who did not deliver in such facilities. Across the sample, $41.3 \%$ of respondents reported having health insurance, of which $93.8 \%$ reported being covered by Ghana's National Health Insurance scheme.

The bivariate analysis indicated that women who delivered in healthcare facilities had fewer issues with affordability, accessibility, and social access, and were more likely to have high previous healthcare utilization, than women who delivered at home (Table 3). Although availability variables were reported to be a "big problem" by more than 4 out of 10 women, they did not significantly influence facility-based delivery rates. Acceptability variables were not considered a major problem for most women, nor were they significantly associated with delivery in a healthcare facility.

In all, $8.3 \%$ of the sample population was excluded from the multivariate analysis. No significant differences were observed in terms of facility-based delivery rates or literacy between the included and excluded women. However, women with missing data were slightly younger (mean 25.6 vs 29.0 years; $P<0.001$ ) and reported fewer previous births (mean 2.8 vs $3.7 ; P=0.003$ ) than the women included in the multivariate analysis.

In multivariate analysis examining clusters of related variables separately (Table 2 ), the sociodemographic variables most strongly associated with facility-based delivery were age at first marriage, maternal literacy, partner's education level, not being in a polygamous relationship, urban residence, traditional or Muslim religion, and

Table 1

The " 5 As of Access" framework as assessed in the 2008 Ghana Demographic Health Survey.

\begin{tabular}{|c|c|c|}
\hline 5 As of Access category & 5 As of Access definition & DHS item \\
\hline Affordability & $\begin{array}{l}\text { How the provider's charges relate to the patient's ability } \\
\text { and willingness to pay for services }\end{array}$ & $\begin{array}{l}\text { Mean wealth index } \\
\text { Health insurance coverage } \\
\text { Cost as a perceived barrier }{ }^{\mathrm{a}}\end{array}$ \\
\hline Availability & $\begin{array}{l}\text { Extent to which the provider has the resources, such as } \\
\text { personnel and technology, to meet his or her patients' needs }\end{array}$ & $\begin{array}{l}\text { Concern about there being no provider at the facility }{ }^{\mathrm{a}} \\
\text { Concern about there being no medication available at the facility }\end{array}$ \\
\hline Accessibility & Geographic accessibility & $\begin{array}{l}\text { Distance to nearest facility }{ }^{\mathrm{a}} \\
\text { Having to find transport }{ }^{\mathrm{a}} \\
\text { Rural vs urban residence } \\
\text { Region of residence }\end{array}$ \\
\hline Accommodation & $\begin{array}{l}\text { Extent to which the provider's operation is organized in ways } \\
\text { that meet the constraints and preferences of the patient }\end{array}$ & $\mathrm{N} / \mathrm{A}$ \\
\hline Acceptability & $\begin{array}{l}\text { Degree to which the patient is comfortable with the } \\
\text { characteristics of the provider, and vice versa }\end{array}$ & Concern about there being no female provider available at the facility \\
\hline Social access & $\mathrm{N} / \mathrm{A}^{\mathrm{b}}$ & $\begin{array}{l}\text { Needing permission to seek healthcare }{ }^{a} \\
\text { Not wanting to go to healthcare facility alone }{ }^{a} \\
\text { Who has final say in healthcare decisions? }\end{array}$ \\
\hline
\end{tabular}

Abbreviations: DHS, Demographic Health Survey; N/A, not applicable.

${ }^{\text {a }}$ Question focused on barriers to utilization of general healthcare services (big problem vs not a big problem).

b Social access was not included in the original 5 As of Access model. The working definition of this category was the degree to which social and cultural factors influence care-seeking behavior. 
Table 2

Sociodemographic characteristics of a weighted sample from the 2008 Ghana Demographic Health, stratified by place of delivery. ${ }^{\text {a }}$

\begin{tabular}{|c|c|c|c|c|}
\hline Variable & Weighted sample $(\mathrm{n}=1102)$ & $\begin{array}{l}\text { Women who delivered in a } \\
\text { healthcare facility ( } \mathrm{n}=612 ; 55.5 \%)\end{array}$ & $\begin{array}{l}\text { Women who did not deliver in a } \\
\text { healthcare facility }(\mathrm{n}=490 ; 44.5)\end{array}$ & $P$ value $^{\mathrm{b}}$ \\
\hline \multicolumn{5}{|l|}{ Age-related cluster } \\
\hline Age, y & 28.6 & 28.6 & 28.6 & 0.981 \\
\hline Age at first birth, y & 20.2 & 20.8 & 19.3 & 0.001 \\
\hline Age at first marriage, y & 19.0 & 19.8 & 18.0 & $<0.001$ \\
\hline Age difference, $\mathrm{y}^{\mathrm{c}}$ & -7.2 & -6.7 & -7.9 & 0.045 \\
\hline \multicolumn{5}{|l|}{ Birth-related cluster } \\
\hline Total births & 3.6 & 3.2 & 4.0 & $<0.001$ \\
\hline Living children & 3.2 & 2.9 & 3.5 & $<0.001$ \\
\hline Children aged $\leq 5 \mathrm{y}$ in the household & 2.0 & 1.9 & 2.2 & 0.002 \\
\hline \multicolumn{5}{|l|}{ Education cluster } \\
\hline \multicolumn{5}{|l|}{ Highest level of education } \\
\hline No education & 34.9 & 22.9 & 50.2 & $<0.001$ \\
\hline Primary school & 24.0 & 22.7 & 26.9 & \\
\hline Secondary school & 37.6 & 49.5 & 22.7 & \\
\hline Higher education & 3.4 & 5.9 & 0.2 & \\
\hline \multicolumn{5}{|l|}{ Literacy } \\
\hline Cannot read at all & 69.6 & 55.2 & 87.1 & $<0.001$ \\
\hline Can read partial sentences & 11.0 & 15.2 & 5.2 & \\
\hline Can read complete sentences & 19.4 & 28.7 & 7.7 & \\
\hline \multicolumn{5}{|l|}{ Partner's level of education } \\
\hline No education & 29.3 & 16.6 & 45.0 & $<0.001$ \\
\hline Primary school & 11.2 & 9.4 & 13.3 & \\
\hline Secondary school & 51.5 & 60.9 & 40.0 & \\
\hline Higher education & 8.0 & 13.1 & 1.7 & \\
\hline \multicolumn{5}{|l|}{ Marriage cluster } \\
\hline Married & 73.2 & 75.4 & 71.4 & 0.307 \\
\hline No polygamist union & 73.2 & 78.4 & 66.8 & 0.002 \\
\hline \multicolumn{5}{|l|}{ Region and ethnicity clusters } \\
\hline \multicolumn{5}{|l|}{ Religion } \\
\hline Christian & 67.6 & 76.2 & 57.0 & $<0.001$ \\
\hline Muslim & 21.4 & 18.0 & 25.6 & \\
\hline Traditional $^{\mathrm{d}}$ & 6.0 & 1.8 & 11.2 & \\
\hline None & 5.0 & 4.0 & 6.2 & \\
\hline \multicolumn{5}{|l|}{ Ethnicity } \\
\hline Akan & 41.0 & 63.8 & 36.2 & $<0.001$ \\
\hline Ga-Adangbe & 4.7 & 53.1 & 46.9 & \\
\hline Ewe & 14.1 & 65.1 & 34.9 & \\
\hline Guan & 3.3 & 40.9 & 59.1 & \\
\hline Mole-Dagbane & 21.3 & 46.1 & 53.9 & \\
\hline Grussi & 3.8 & 65.6 & 34.4 & \\
\hline Gruma & 6.9 & 22.5 & 77.5 & \\
\hline Mande & 0.5 & 83.6 & 16.4 & \\
\hline Other & 4.8 & 51.7 & 48.3 & \\
\hline \multicolumn{5}{|l|}{ Prior utilization cluster } \\
\hline PNC from a doctor, nurse, or midwife & 84.2 & 92.7 & 71.3 & $<0.001$ \\
\hline Told about pregnancy complications at PNC visit & 68.4 & 77.1 & 54.2 & $<0.001$ \\
\hline Told where to go for complications during PNC visit & 92.9 & 92.8 & 93.1 & 0.918 \\
\hline PNC visits & 5.8 & 6.6 & 4.5 & $<0.001$ \\
\hline
\end{tabular}

Abbreviation: PNC, prenatal care.

a Values are given as mean or percentage, unless otherwise indicated.

b Means compared using binary logistic regression for continuous variables and $\chi^{2}$ test for categorical variables.

c A negative value indicates that the woman was younger than her partner.

d Traditional religion refers to beliefs and practices reflective of indigenous peoples, typically including communication with ancestors and other spirits.

Akan ethnicity (Tables 2 and 3). These variables were combined in a multivariate model (Table 4).

Models 2-5 in Table 5 illustrate the relationship between accessrelated variable clusters and facility-based delivery. In terms of affordability, both wealth index and having health insurance were associated with a more than doubling of a woman's likelihood of delivery in a healthcare facility. In terms of accessibility, urban location was associated with an increased likelihood of facility-based delivery; the odds ratio (OR) was 6.3 (95\% confidence interval [CI], 3.8-10.6; $P<0.001$ ). By contrast, living in the Northern region of Ghana was associated with a reduced likelihood of facility-based delivery; the OR was 0.2 (95\% CI, $0.1-0.4 ; P<0.001)$. Notably, distance to the facility and finding transport were not significantly related to facilitybased delivery.
The number of prenatal visits correlated with facility-based delivery, whereas being told where to go for complications at the prenatal care visit decreased the likelihood of delivery at a healthcare facility, although this latter finding may reflect sample size issues (Table 6). The social access variables of needing permission to go to a healthcare facility and not participating in the final healthcare decision were both significantly associated with a lower likelihood of delivery in such a facility (Table 6).

When the significant variables from all previous models were entered into a single model (data not shown), wealth index, health insurance, urban location, and maternal literacy were all associated with an increased likelihood of facility-based delivery, whereas being told where to go in the event of complications during prenatal visits and traditional and Muslim religion were associated with a 
Table 3

Access-related characteristics of a weighted sample from the 2008 Ghana Demographic Health Survey, stratified by place of delivery.,

\begin{tabular}{|c|c|c|c|c|}
\hline Variable & Weighted sample ( $\mathrm{n}=1102)$ & $\begin{array}{l}\text { Women who delivered } \\
\text { in a healthcare facility } \\
(\mathrm{n}=612 ; 55.5 \%)\end{array}$ & $\begin{array}{l}\text { Women who did not deliver } \\
\text { in a healthcare facility } \\
(\mathrm{n}=490 ; 44.5 \%)\end{array}$ & $P$ value ${ }^{\mathrm{c}}$ \\
\hline \multicolumn{5}{|l|}{ Affordability cluster } \\
\hline Mean wealth index, scale of $1-5$ & 2.7 & 3.3 & 1.9 & $<0.001$ \\
\hline Covered by health insurance & 41.3 & 57.3 & 21.3 & $<0.001$ \\
\hline Showed valid NHIS card if answered "yes" to health insurance & 69.6 & 68.8 & 71.9 & 0.784 \\
\hline Cost of treatment as a barrier to seeking healthcare ${ }^{\mathrm{d}}$ & 47.3 & 39.5 & 57.1 & $<0.001$ \\
\hline \multicolumn{5}{|l|}{ Availability cluster } \\
\hline Concern no provider available as a barrier to seeking healthcare ${ }^{\mathrm{d}}$ & 41.3 & 41.9 & 40.4 & 0.741 \\
\hline Concern no drugs available as a barrier to seeking healthcare ${ }^{\mathrm{d}}$ & 42.5 & 40.7 & 44.8 & 0.367 \\
\hline \multicolumn{5}{|l|}{ Accessibility cluster } \\
\hline Distance to facility as a barrier to seeking healthcare ${ }^{\mathrm{d}}$ & 29.7 & 23.8 & 37.1 & 0.001 \\
\hline Having to find transport as a barrier to seeking healthcare ${ }^{d}$ & 29.1 & 23.6 & 35.9 & 0.004 \\
\hline Urban residence & 37.0 & 55.0 & 14.6 & $<0.001$ \\
\hline \multicolumn{5}{|l|}{ Region of residence } \\
\hline Greater Accra & 10.8 & 79.4 & 20.6 & $<0.001$ \\
\hline Western or Central & 21.5 & 56.1 & 43.9 & \\
\hline Volta or Eastern & 17.7 & 56.9 & 43.1 & \\
\hline Ashanti or Brong Ahafo & 24.0 & 67.2 & 32.8 & \\
\hline Northern & 18.5 & 23.0 & 77.0 & \\
\hline Upper West or Upper East & 7.5 & 60.1 & 39.9 & \\
\hline \multicolumn{5}{|l|}{ Acceptability cluster } \\
\hline Concern no female provider available as a barrier to seeking healthcare ${ }^{\mathrm{d}}$ & 18.8 & 16.4 & 21.7 & 0.101 \\
\hline \multicolumn{5}{|l|}{ Social access cluster } \\
\hline Needing permission as a barrier to seeking healthcare ${ }^{\mathrm{d}}$ & 9.5 & 6.7 & 13.0 & 0.007 \\
\hline Not wanting to go alone as a barrier to seeking healthcare ${ }^{\mathrm{d}}$ & 15.8 & 12.7 & 19.8 & 0.008 \\
\hline \multicolumn{5}{|l|}{ Who has the final say in healthcare decisions? } \\
\hline Woman alone or with partner & 59.9 & 63.6 & 55.2 & 0.040 \\
\hline Partner or someone else & 40.1 & 36.4 & 44.8 & \\
\hline
\end{tabular}

Abbreviation: NHIS, National Health Insurance Scheme.

a Values are given as mean or percentage, unless otherwise indicated.

b Accommodation variables not included.

c Means compared using binary logistic regression for continuous variables and $\chi^{2}$ test for categorical variables.

d Respondents rated the factor as "a big problem."

decreased likelihood of facility-based delivery. In the final modelModel 6-the non-significant variables were removed and results suggested that wealth index, having health insurance, being told where to go for complications during prenatal care, maternal literacy, and Muslim religion were the factors most strongly associated with facility-based delivery, even after adjusting for urban status (Tables 5 and 6). In the terminology of the 5 As of Access, affordability is one of the most important access-related factors in influencing facility-based delivery. The influence of Muslim religion indicates the importance of social access.

Table 4

Multivariate logistic regression analysis of sociodemographic variables associated with facility-based delivery in the 2008 Ghana Demographic Health Survey ( $n=1010$ ).

\begin{tabular}{llc}
\hline Variable & $\begin{array}{l}\text { Model 1 } \\
\text { Facility-based delivery } \\
\text { OR }(95 \% \text { CI })\end{array}$ & P value \\
& $1.1(0.9-1.1)$ & 0.09 \\
\hline Age at first marriage & Reference & \\
Maternal literacy & $3.0(1.4-6.0)$ & $<0.01$ \\
$\quad$ Cannot read & $2.3(1.3-4.2)$ & $<0.01$ \\
Can read partial sentences & & \\
Can read complete sentences & Reference & 0.31 \\
Partner's education level & $1.5(0.7-3.0)$ & $<0.05$ \\
$\quad$ No education & $1.7(1.0-2.9)$ & 0.01 \\
Primary & $4.6(1.5-13.9)$ & 0.83 \\
Secondary & $0.9(0.6-1.6)$ & $<0.001$ \\
Higher education & $5.2(3.0-8.9)$ & $<0.05$ \\
No polygamist union & $0.4(0.1-0.9)$ & 0.01 \\
Urban residence & $0.4(0.2-0.8)$ & 0.96 \\
Traditional religion & $1.0(0.6-1.6)$ & \\
Muslim religion & & \\
Akan ethnicity & & \\
\hline
\end{tabular}

Abbreviations: $\mathrm{CI}$, confidence interval; OR, odds ratio.
Other than the influence of Muslim religion, social access factors were not sufficiently robust to warrant inclusion in the final multivariate model. Once affordability and accessibility variables were entered into the model (Table 5), the impact of social access was markedly attenuated. Table 6 illustrates how the ORs and levels of significance for the strongest social access variables (i.e. needing permission to go to a healthcare facility and not participating in the final healthcare decision) changed with the addition of each factor included in the final models of the other access variables (Table 5). Individually, maternal literacy, health insurance coverage, and wealth index each overpowered the statistical significance of the social access variables.

Traditional or Muslim religion did not substantially influence social access factors. This finding was noteworthy given that needing permission to seek healthcare was associated with traditional religious practice $(P=0.01)$. When all factors were entered together, health insurance coverage $(\mathrm{OR}, 2.9 ; P<0.001)$, ability to read at least partial sentences (OR, 2.7; $P<0.01$ ), and wealth index (OR, $2.1 ; P<0.001)$ remained statistically significant, whereas religion and the social access factors did not. This finding suggests that social access factors are important determinants because they are linked to lower educational attainment, lack of health insurance, and lower household wealth.

\section{Discussion}

Analysis of the 2008 Ghana DHS suggested that affordability was the most important access barrier related to facility-based delivery. Multivariate analysis indicated that even after adjusting for urban status and maternal literacy, health insurance coverage was associated with a 3-fold increase in the odds of facility delivery, while each unit increase on a 5-point wealth index nearly doubled the odds of 
Table 5

Multivariate logistic regression analysis of access-related variables associated with facility-based delivery in the 2008 Ghana Demographic Health Survey ( $\mathrm{n}=1010$ ).

\begin{tabular}{|c|c|c|c|c|c|}
\hline Variable & $\begin{array}{l}\text { Model } 2 \\
\text { OR }(95 \% \text { CI })\end{array}$ & $\begin{array}{l}\text { Model } 3 \\
\text { OR }(95 \% \mathrm{CI})\end{array}$ & $\begin{array}{l}\text { Model } 4 \\
\text { OR }(95 \% \mathrm{CI})\end{array}$ & $\begin{array}{l}\text { Model } 5 \\
\text { OR }(95 \% \mathrm{CI})\end{array}$ & $\begin{array}{l}\text { Model } 6 \\
\text { OR }(95 \% \text { CI })\end{array}$ \\
\hline \multicolumn{6}{|l|}{ Affordability } \\
\hline Wealth index & $2.3(2.0-2.7)^{\mathrm{b}}$ & & & & $1.8(1.4-2.2)^{\mathrm{b}}$ \\
\hline Covered by health insurance & $2.7(1.8-4.2)^{\mathrm{b}}$ & & & & $2.8(1.9-4.2)^{b}$ \\
\hline Cost of treatment as a barrier & $0.7(0.4-1.0)$ & & & & \\
\hline \multicolumn{6}{|l|}{ Accessibility } \\
\hline Distance as a barrier & & $0.6(0.3-1.2)$ & & & \\
\hline Finding transport & & $1.0(0.5-2.2)$ & & & \\
\hline Urban location & & $6.3(3.8-10.6)^{b}$ & & & $1.9(1.0-3.6)^{\mathrm{c}}$ \\
\hline \multicolumn{6}{|l|}{ Region } \\
\hline Accra & & Reference & & & \\
\hline Western or Central & & $0.7(0.3-1.8)$ & & & \\
\hline Volta or Eastern & & $1.1(0.4-3.1)$ & & & \\
\hline Ashanti or Brong Ahafo & & $1.4(0.5-3.6)$ & & & \\
\hline Northern & & $0.2(0.1-0.4)^{b}$ & & & \\
\hline Upper West or Upper East & & $1.5(0.5-4.2)$ & & & \\
\hline \multicolumn{6}{|l|}{ Prior utilization } \\
\hline PNC visits with MD & & & $1.4(0.8-2.6)$ & & \\
\hline PNC visits with nurse or midwife & & & $1.6(0.9-2.8)$ & & \\
\hline Told where to go for complications at PNC visit & & & $0.4(0.3-0.7)^{\mathrm{b}}$ & & $0.7(0.6-0.9)^{\mathrm{b}}$ \\
\hline Told about complications at PNC visit & & & $0.4(0.1-1.0)$ & & \\
\hline Number of PNC visits & & & $1.5(1.0-2.2)^{\mathrm{c}}$ & & \\
\hline \multicolumn{6}{|l|}{ Social access } \\
\hline Needing permission & & & & $0.5(0.3-0.9)^{\mathrm{c}}$ & \\
\hline Not wanting to go alone & & & & $0.7(0.4-1.0)$ & \\
\hline Not having final say in healthcare decisions & & & & $0.7(0.5-0.9)^{\mathrm{c}}$ & \\
\hline \multicolumn{6}{|l|}{ Maternal literacy } \\
\hline Cannot read & & & & & Reference \\
\hline Can read partial sentences & & & & & $2.7(1.3-5.7)^{\mathrm{d}}$ \\
\hline Can read complete sentences & & & & & $1.6(0.9-3.0)$ \\
\hline Traditional religion $^{\mathrm{a}}$ & & & & & $0.6(0.3-1.6)$ \\
\hline Muslim religion & & & & & $0.5(0.3-0.9)^{\mathrm{c}}$ \\
\hline
\end{tabular}

Abbreviations: $\mathrm{CI}$, confidence interval, OR, odds ratio; $\mathrm{MD}$, medical doctor; PNC, prenatal care.

a Traditional religion refers to beliefs and practices reflective of indigenous peoples, typically including communication with ancestors and other spirits.

b $P<0.001$.

c $P<0.05$.

d $P<0.01$.

facility-based delivery. By contrast, availability, accessibility (with the exception of urban status), acceptability, and social access variables were not significant in the final multivariate models.

Social access variables, including needing permission to visit a healthcare facility and not being involved in the final decision regarding healthcare, were significantly associated with a lowered likelihood of facility-based delivery when examined individually. However, multivariate analysis suggested that these variables reflect maternal literacy, health insurance coverage, and possibly household wealth. In other words, social access factors may influence maternal literacy, health insurance, and household wealth. For example, women who require permission to seek healthcare might also need permission to attend school, obtain health insurance, or get a job. As a consequence, they may have low literacy, be less likely to have health insurance, or less likely to have a steady income and accumulate family wealth. These social access factors could in turn influence facility-based delivery rates. Such a mediating relationship seems plausible given the findings of the present study.

Many African studies have shown that the poorest women in a community are the least likely to use delivery services [4,5,9,14-20]. Several reports have highlighted the direct relationship between health insurance coverage and facility-based delivery rates $[2,16,21-$

Table 6

Multivariate logistic regression analysis of social access-related variables associated with facility-based delivery in the 2008 Ghana Demographic Health Survey ( $\mathrm{n}=1010$ ).

\begin{tabular}{|c|c|c|c|c|c|c|}
\hline Variable & $\begin{array}{l}\text { Model } 1 \\
\text { OR (95\% CI) }\end{array}$ & $\begin{array}{l}\text { Model } 2 \\
\text { OR }(95 \% \mathrm{CI})\end{array}$ & $\begin{array}{l}\text { Model } 3 \\
\text { OR }(95 \% \mathrm{CI})\end{array}$ & $\begin{array}{l}\text { Model } 4 \text { OR } \\
(95 \% \mathrm{CI})\end{array}$ & $\begin{array}{l}\text { Model } 5 \text { OR } \\
(95 \% \mathrm{CI})\end{array}$ & $\begin{array}{l}\text { Model } 6 \text { OR } \\
(95 \% \mathrm{CI})\end{array}$ \\
\hline Needing permission & $0.5(0.3-0.8)^{\mathrm{b}}$ & $0.6(0.3-1.0)$ & $0.6(0.3-1.1)$ & $0.7(0.4-1.4)$ & $0.5(0.3-0.9)^{\mathrm{c}}$ & $1.0(0.5-1.8)$ \\
\hline Not having final say in healthcare decisions & $0.7(0.5-1.0)^{\mathrm{c}}$ & $0.8(0.5-1.1)$ & $0.7(0.5-1.0)$ & $0.9(0.6-1.3)$ & $0.7(0.5-0.9)^{\mathrm{c}}$ & $0.9(0.6-1.4)$ \\
\hline \multicolumn{7}{|l|}{ Maternal literacy } \\
\hline Cannot read & & Reference & & & & \\
\hline Can read partial sentences & & $4.4(2.3-8.3)^{\mathrm{d}}$ & & & & $2.7(1.3-5.5)^{\mathrm{b}}$ \\
\hline Can read complete sentences & & $6.5(3.7-11.4)^{\mathrm{d}}$ & & & & $1.7(0.9-3.2)$ \\
\hline Covered by health insurance & & & $4.7(3.1-7.0)^{d}$ & & & $2.9(1.9-4.3)^{\mathrm{d}}$ \\
\hline Wealth index & & & & $2.5(2.1-2.9)^{\mathrm{d}}$ & & $2.1(1.8-2.5)^{\mathrm{d}}$ \\
\hline Traditional religion $^{\mathrm{a}}$ & & & & & $0.1(0.1-0.4)^{\mathrm{d}}$ & $0.6(0.2-1.5)$ \\
\hline Muslim religion & & & & & $0.5(0.3-0.8)^{\mathrm{b}}$ & $0.6(0.4-1.0)$ \\
\hline
\end{tabular}

Abbreviations: CI, confidence interval, OR, odds ratio.

a Traditional religion refers to beliefs and practices reflective of indigenous peoples, typically including communication with ancestors and other spirits.

b $P<0.01$.

c $P<0.05$.

d $P<0.001$. 
23]. However, none of these studies compared social access and affordability factors in their analyses. The findings of the present study suggest that social access is a valuable construct, yet its impact may be difficult to discern independently from the more powerful poverty-related variables.

The National Health Insurance scheme in Ghana fully covers both prenatal and delivery care. Nevertheless, only $41.3 \%$ of the present study sample reported having such insurance. This observation may be a function of the timing of the 2008 Ghana DHS: a national system of health insurance was adopted in principle in 2003 but did not become widely available until several years later. The Ghana DHS data were collected in 2008; despite insurance being available at roadside kiosks and healthcare centers, it is not implausible to suggest that women had not yet 'opted in' to the scheme in sufficient numbers. Nearly half of all women in the present study reported cost of treatment as a "big problem" when seeking healthcare services. Indeed, this factor was the most frequent barrier reported. Research is needed to examine whether Ghana's national opt-in insurance scheme is the optimum method to reach the majority of its population or if an alternative approach, such as automatic enrollment, should be considered. Research is also needed to explore the implications of increased uptake of health insurance over time, especially given that the national scheme was still in its infancy at the time of the 2008 Ghana DHS.

Several limitations of the present study should be considered. The use of cross-sectional data did not allow causation to be determined. In addition, analyses were limited to only those items assessed in the 2008 Ghana DHS. Thus, potentially important factors that may influence access could not be evaluated in the present study. These factors included the attitude of maternity staff, perceived or actual quality of the facilities, and the importance women place on characteristics of the delivery environment. The present study also combined many different types of facilities into a single unit for the purposes of the analysis. Further research with more complex analyses is required to help understand the distinctions between facilities, both in terms of perceived access and ultimate delivery outcomes.

In summary, the results of the present study demonstrated that in Ghana in 2008, affordability variables were an appreciable correlate of facility-based delivery among women who gave birth within the previous year. Accessibility and social access variables were also associated with facility-based delivery; however, affordability variables were the strongest in the multivariate models. Taken together, the results of the present study indicated that the 5 As of Access framework, with the addition of a social access category, represented a valid method to conceptualize access to healthcare in low-income countries. The data illustrated that improving affordability by making health insurance available to all women might not necessarily improve access and utilization if social rules dictate that they must first seek permission before attending a clinic. Future research is needed to explore the concept of social access in greater detail, generate potential tools to measure all types of access, and test potential interventions to address access-related barriers to seeking healthcare.

\section{References}

[1] Lawn JE, Kerber K, Enweronu-Laryea C, Massee Bateman O. Newborn survival in low resource settings-are we delivering? BJOG 2009;116(Suppl. 1):49-59.

[2] Aremu O, Lawoko S, Dalal K. Neighborhood socioeconomic disadvantage, individual wealth status and patterns of delivery care utilization in Nigeria: a multilevel discrete choice analysis. Int J Womens Health 2011;3:167-74.

[3] Bazant ES, Koenig MA, Fotso JC, Mills S. Women's use of private and government health facilities for childbirth in Nairobi's informal settlements. Stud Fam Plann 2009;40(1):39-50.

[4] Ahmed S, Creanga AA, Gillespie DG, Tsui AO. Economic status, education and empowerment: implications for maternal health service utilization in developing countries. PLoS One 2010;5(6):e11190.

[5] Ochako R, Fotso JC, Ikamari L, Khasakhala A. Utilization of maternal health services among young women in Kenya: insights from the Kenya Demographic and Health Survey, 2003. BMC Pregnancy Childbirth 2011;11:1.

[6] Adanu RM. Utilization of obstetric services in Ghana between 1999 and 2003. Afr J Reprod Health 2010;14(3):153-8.

[7] Babalola S, Fatusi A. Determinants of use of maternal health services in Nigerialooking beyond individual and household factors. BMC Pregnancy Childbirth 2009;9:43.

[8] Woldemicael G. Do women with higher autonomy seek more maternal health care? Evidence from Eritrea and Ethiopia. Health Care Women Int 2010;31(7): 599-620.

[9] Hounton S, Chapman G, Menten J, De Brouwere V, Ensor T, Sombié I, et al. Accessibility and utilisation of delivery care within a Skilled Care Initiative in rural Burkina Faso. Trop Med Int Health 2008;13(Suppl. 1):44-52.

[10] Wanjira C, Mwangi M, Mathenge E, Mbugua G, Ng'ang'a Z. Delivery practices and associated factors among mothers seeking child welfare services in selected health facilities in Nyandarua South District, Kenya. BMC Public Health 2011;11:360.

[11] Penchansky R, Thomas JW. The concept of access: definition and relationship to consumer satisfaction. Med Care 1981;19(2):127-40.

[12] McLaughlin CG, Wyszewianski L. Access to care: remembering old lessons. Health Serv Res 2002;37(6):1441-3.

[13] Rutstein SO, Rojas G. Guide to DHS Statistics: Demographic and Health Surveys Methodology. http://www.measuredhs.com/pubs/pdf/DHSG1/Guide_to_DHS_ Statistics_290ct2012_DHSG1.pdf. Published September 2006.

[14] Fotso IC, Ezeh A, Madise N, Ziraba A, Ogollah R. What does access to maternal care mean among the urban poor? Factors associated with use of appropriate maternal health services in the slum settlements of Nairobi, Kenya. Matern Child Health J 2009;13(1):130-7.

[15] Fotso JC, Ezeh AC, Essendi H. Maternal health in resource-poor urban settings: how does women's autonomy influence the utilization of obstetric care services? Reprod Health 2009;6:9.

[16] Hong R, Ayad M, Ngabo F. Being insured improves safe delivery practices in Rwanda. J Community Health 2011;36(5):779-84.

[17] Kruk ME, Prescott MR, Galea S. Equity of skilled birth attendant utilization in developing countries: financing and policy determinants. Am J Public Health 2008;98(1):142-7.

[18] Montagu D, Yamey G, Visconti A, Harding A, Yoong J. Where do poor women in developing countries give birth? A multi-country analysis of demographic and health survey data. PLoS One 2011;6(2):e17155.

[19] Spangler SA, Bloom SS. Use of biomedical obstetric care in rural Tanzania: the role of social and material inequalities. Soc Sci Med 2010;71(4):760-8.

[20] Zere E, Oluwole D, Kirigia JM, Mwikisa CN, Mbeeli T. Inequities in skilled attendance at birth in Namibia: a decomposition analysis. BMC Pregnancy Childbirth 2011;11:34.

[21] Kruk ME, Rockers PC, Mbaruku G, Paczkowski MM, Galea S. Community and health system factors associated with facility delivery in rural Tanzania: a multilevel analysis. Health Policy 2010;97(2-3):209-16.

[22] Penfold S, Harrison E, Bell J, Fitzmaurice A. Evaluation of the delivery fee exemption policy in ghana: population estimates of changes in delivery service utilization in two regions. Ghana Med J 2007;41(3):100-9.

[23] Smith KV, Sulzbach S. Community-based health insurance and access to maternal health services: evidence from three West African countries. Soc Sci Med 2008;66(12):2460-73.

\section{Conflict of interest}

The authors have no conflicts of interest. 